\title{
Understanding how outcomes are measured in workplace physical activity interventions: a scoping review
}

Stacey Johnson ${ }^{1,3^{*}} \mathbb{D}$, Jean-Philippe Regnaux ${ }^{3,4,5}$, Adrien Marck ${ }^{1,2}$, Geoffroy Berthelot ${ }^{1,2,6}$, Joana Ungureanu ${ }^{1,3}$ and Jean-François Toussaint ${ }^{1,2,5}$

\begin{abstract}
Background: An inverse relationship exists between physical activity and many non-communicable diseases, such as obesity. Given the daily time spent, a logical domain to reach an adult population for intervention is within and around the workplace. Many government bodies, including the World Health Organization (WHO), include worksite health promotions (WHPs) targeted at increasing physical activity as a public health intervention. The aim of this scoping review was to determine what was measured (outcomes) and how they were measured (evaluation tools) during workplace physical activity interventions in order to identify gaps and implications for policies and practice.

Methods: A scoping review was executed in April 2017 via PubMed, SPORTDiscus, EBSCOhost and the Cochrane Library. This search included articles published between January 2008 to February 2017 in order to coincide with the WHO's Global Plan of Action on Worker's Health. Extracted information was arranged into data collection grids. Cross-analysis of measured outcomes with their corresponding evaluation tools was completed. A quality assessment based on study design was executed.

Results: Identification of 732 records was made and ultimately 20 studies and reviews that met criteria were selected. Researchers themed 9 primary measured outcomes. Studies utilized various forms of both objective and subjective evaluation methods. Three primary evaluation methods were categorized: biologic, electronic and declarative tools. The researchers discovered 92 unique tools: 27 objective and 65 subjective, within these parameters.

Conclusion: Study quality, measurement tools and data collection were heterogeneous making analysis of effect comparisons problematic and unreliable. Much of the published research does not employ robust statistical analysis making effects difficult to ascertain. Considering the variety of both measured outcomes and evaluation tools, only educated inferences can be made as to the effectiveness and efficiency of WHPs. More standardized measurement practices are therefore suggested for assessment efficiency.
\end{abstract}

Keywords: Workplace physical activity program/promotion, Workplace health promotion, Outcome measures, Evaluation tools, Heterogeneity, Sustainability, Scoping review

\footnotetext{
* Correspondence: stacey.johnson@eleve.ehesp.fr

${ }^{1}$ Institut de Recherche bio-Médicale et d'Épidémiologie du Sport (IRMES), Institut National du Sport de l'Expertise et de la Performance (INSEP), 11 avenue du Tremblay, 75012 Paris, France

3École des hautes études en santé publique (EHESP), Université Sorbonne

Paris Cité, Rennes, France

Full list of author information is available at the end of the article
}

(c) The Author(s). 2018 Open Access This article is distributed under the terms of the Creative Commons Attribution 4.0 International License (http://creativecommons.org/licenses/by/4.0/), which permits unrestricted use, distribution, and reproduction in any medium, provided you give appropriate credit to the original author(s) and the source, provide a link to the Creative Commons license, and indicate if changes were made. The Creative Commons Public Domain Dedication waiver (http://creativecommons.org/publicdomain/zero/1.0/) applies to the data made available in this article, unless otherwise stated. 


\section{Background}

The obesity epidemic has reached an all-time high. According to body mass index, just under 2 billion adults are reportedly overweight; among them, half a billion people are obese [1, 2]. Multiple factors are implicated as causes including an increased consumption of calorie dense foods, lower amounts of daily physical activity, increased screen-time both at work and during leisure time, unsupportive environments such as lack of sidewalks or unsafe bike trails as well as genetics [3, 4]. Strong evidence points to physical inactivity increasing the risk of many major non-communicable diseases (NCDs) $[1,5,6]$, which make up approximately $70 \%$ of the present total burden of disease [7]. Worldwide, NCDs represent a major burden to national healthcare systems. In 2011, the World Economic Forum reported that $63 \%$ of deaths could be attributed to NCDs and cost over 30 trillion US dollars [5]. Increased physical activity (PA) can help mitigate many of these disease risk factors and should be a fundamental component of public health work [7].

Much of the adult population falls short of the PA recommendations. Encouraging people to be physically active has numerous benefits beyond health, to include the economy and environment. Previous studies suggest that promoting active modes of transportation can be associated with positive health impact assessments and has the potential to save billions per year by reducing pollution and oil consumption $[8,9]$. To improve health through prevention and chronic disease management, adult guidelines recommend $150 \mathrm{~min}$ of moderate intensity aerobic physical activity or $75 \mathrm{~min}$ of vigorous intensity physical activity (MVPA) per week. Additional benefits are possible with increased duration and strength training $[4,10]$. Although such recommendations are widely recognized, adults continue to widen the gap by increasing sedentary behaviors. Latest factsheets from the World Health Organization (WHO) European Region report the percentage of adults attaining appropriate amounts of physical activity fall below acceptable levels for both sexes: Italy 36\%, Germany 39\%, France $45 \%$ and England which fares better at $60 \%[2,4,11]$.

\section{Workplace health promotions}

Importance has been placed on health promotion since the 1950's and has undergone multiple charters and declarations. The most notable being the 1986 Ottawa Charter for Health Promotion and the most recent; WHO's Global Plan of Action on Worker's Health 2008-2017 [12, 13]. To address the escalation of sedentary behavior, WHO Europe recognized the advantages of the workplace as a medium to reach much of the adult population at multiple levels both directly and indirectly to influence behaviors [4]. Workplace Health
Promotion programs (WHPs) are employer initiatives directed at improving the health and wellbeing of workers and their dependents. At their core, they support primary, secondary and tertiary prevention efforts [14].

WHPs often focus on factors such as physical activity, sports, exercise classes and behavior change to increase physical activity levels [15-17]. The work setting is also advantageous for corporations: programs including a physical activity component have the potential to increase employee productivity, reduce absenteeism, act as recruitment and retention tools, reduce health care costs and increase physical activity levels outside the workplace $[8,18,19]$. These settings can also counter common barriers such as lack of time, family duties and low motivation [20, 21].

Many studies on WHPs have been conducted with a myriad of outcomes being measured. In order to determine the impact and long term effectiveness, the link relating the measured outcomes to the promotion or program is very important. Thus far, there is no known standard for evaluating the impact of these promotions/ programs or their outcomes. A variety of tools and measures have been used and adapted for specific study purposes, including blood tests, accelerometers and questionnaires, mixing both objective and subjective evaluation tools. Cost, time and assessment for some of these can be of concern for large scale studies due to restricted budgets. Expensive tools can prove to be a barrier for workplaces considering return on investment (ROI) [14, 20, 22, 23]. A vast majority of interventions use self-report measures for levels of PA. Some of these include various forms of diaries, interviews, online journals, pedometer readings and questionnaires. Though possibly biased, the latter are inexpensive, easy to administer, understandable, cost effective and often a preferred method to measure multiple outcomes. Self-report measures have a tendency toward bias and usually overestimate levels of participation compared to objective estimates [24]. Furthermore, universities, research labs and workplaces often create their own questionnaires in order to measure specific outcomes based on personal priority.

Multiple reviews have been published regarding WHPs, yet, none have been expressly concerned with outcomes and evaluation tools. The primary aim of this research was to assess the literature reporting PA changes during WHPs in order to: (1) describe the reported outcome measures, (2) determine the evaluation tools used to evaluate the documented outcomes and (3) detect effects and cross-comparisons of PA interventions. Many public health organizations are concerned with determining which interventions and health promotion programs are most appropriate to achieve sustainable outcomes for both employers and employees 
alike. This research also notes the secondary outcomes that were reported during WHPs (e.g. improved work productivity, sleep quality, nutritional practices, etc.). Many of these outcomes were considered as a secondary outcome of the increased physical activity.

\section{Methods \\ Eligibility criteria}

The methodology of this scoping review was based on methodology set up by The Joanna Briggs Institute [25]. Results have been reported using the PRISMA guidelines for systematic reviews [26]. Prospero has registration for systematic reviews and meta-analysis but currently, none exist for scoping reviews. Three primary criteria for research included: (1) health promotion programs implemented in the workplace, (2) working adults between 18 and 64 years old and (3) physical activity as the primary intervention. Notably, many interventions crossed over into leisure time including, measurements of daily step counts using accelerometers or pedometers. Many studies reported secondary outcomes that were taken into account.

\section{Search strategy}

The search was executed in the English language. Databases included: PubMed, SPORTDiscus, EBSCOhost and the Cochrane Library based on specific keywords. The search included the following word combinations: workplace or worksite or corporation AND physical activity or exercise or fitness or sport AND intervention or program or programme or promotion AND outcomes or benefits or effects AND evaluation methods or evaluation tools or evaluation. Research was conducted on studies and systematic reviews published between January 2008- February 2017. Dates were chosen based on the WHO's Global Plan of Action on Worker's Health 2008-2017 which is a call for public health action to include healthy workplace programmes [27].

\section{Study selection}

Two researchers first examined titles then, the abstracts in coordination with each other. Two alternate researchers were advised in cases of dispute. Finally, full text articles were read and screened for eligibility by one researcher with two other researchers offering recommendations on final selection of studies. Consideration was taken to limit study duplication within systematic reviews (12\%). A relevant sample was purposively selected from the applicable primary studies and systematic reviews. To determine this chosen sample, both small and large scale studies were included in order to capture a variety of interventions, outcomes and measurement tools. Interventions at both the individual level (self-reported steps) and organizational level (team sports) were considered. Only published studies with reported effects were accepted. The primary target was employed, apparently healthy adults. Studies focusing on particular health issues, such as reducing low back pain or chronically ill populations, were eliminated. Workplace health promotions primarily focusing on preventions such as smoking cessation, immunization, alcohol moderation, nutrition and other lifestyle modifications were not included. Individual studies and systematic reviews that did not include clear outcomes or descriptions of the evaluation tools used were discarded. Based on the data extraction forms, studies with many missing data points were excluded. This included type of measurement tool used, outcome being measured (e.g. number of steps, increase of physical activity, weight lost, etc.), sample size, type of physical activity included in the promotion/program, the type of study (e.g. random control trial, before/after, case control, etc.), length of promotion/program, follow-up measurements and results. Low quality studies such as protocols only, expert opinion or lack of specific study design were also omitted.

\section{Data extraction}

Data extraction forms were created for both primary studies and systematic reviews. Outcome measures were determined for the chosen sample of studies and then coded into structured categories. Similar outcomes appeared with multiple terminologies therefore, based on knowledge, 'themed' categories were created. For example, any outcome whose primary purpose was to measure changes in physical activity was included in the 'Physical Activity Level' category. When a study reported measuring a particular outcome, a check was given in the coordinating category indicating this particular outcome had been evaluated in the study. While no statistics were used, a qualitative thematic analysis was completed on the outcomes measured and the evaluation tools used for their measurement purposes. Each tool was qualified as objective or subjective and either validated or of unknown validation. Upon completion, scientific validation of the measurement tools was determined against currently accepted best practices such as the International Physical Activity Questionnaire (IPAQ) which is widely used across multiple worldwide organizations (WHO, NIH and CDC). In order to understand implementation and determine areas of potential improvement, coding also included: (1) intervention type, (2) the method of information communication to participants (e.g. email, meetings, signage, etc.), (3) intervention location (4) timeframe of the intervention, (6) sample size and (5) follow-up timeframes including participant attrition. A hypothesis has been drawn to link 
the outcomes specifically to the physical activity/fitness component of the WHP via the evaluation tool utilized.

The following data were extracted using pre-tested extraction forms:

1. Individual study characteristics (quality grade based on study design, country, worksite, study size and publication journal).

2. Systematic review characteristics (quality grades based on study design, worksites, number of studies included and publication journal).

3. Program characteristics (physical activity promotion program length, location, drop-out rates, follow-up measurements, cost, communication methods, reporting methods and number of simultaneous programs).

4. Primary measured outcomes (physical activity level or fitness). Secondary measured outcomes (motivation/involvement/self-efficacy, self-esteem, nutrition, management/supervisor support of health promotion, anthropometric, bio-chemical parameters, work-related, health-related quality of life and environment).

5. Evaluation tools (questionnaires, electronic devices and biological markers) in accordance with the outcome measured.

6. Synthesis of effects on each of the measured outcomes by reported statistical significance.

\section{Data synthesis}

Data were then summarized using descriptive statistics to outline the characteristics of the included studies. This included information on the type of physical activity or fitness measured (e.g. number of daily steps, sitting time, use of active transportation (walking/biking), moderate to vigorous physical activity, etc.), the evaluation tool(s) used for measurement purposes, whether the tool was an objective or subjective method and the validation confirmation of the tool and finally the unit of measure for physical activity. A narrative synthesis was performed to describe the reported outcome measures and the evaluation tools that were used. These were recorded as electronic, biologic or declarative for each of the themed outcomes.

\section{Study quality}

In order to rate the strength of the scientific evidence and the quality of research [25], an objective simple system of graduation was used for the individual studies proposed by Petrisor [28]. This system of grading awards randomized controlled trial (RCT) designs, including individual RCT and cluster RCTs, with an 'A', quasi-randomized trials, prospective case control and non-RCT receive a 'B', observational studies, controlled before-after, qualitative exploratory, cross-sectional and quasi-experimental designs receive a ' $C$ ' and other evidence including expert opinion receive a ' $\mathrm{D}$ '. A similar but slightly modified grading system was followed for the systematic reviews where specific study design was reported. If no differentiation was reported, the space has been left blank as no grade can be assigned. Grading can be viewed in the results section.

\section{Results}

\section{Selection process}

Search results yielded 204 full text articles in PubMed, 82 results from SPORTDiscus, 416 results through EBSCOhost and 30 results from 9867 records in the Cochrane Library. After removal of duplicates, 402 records remained. Out of these, 268 titles were screened for relevant studies, 100 abstracts were then scanned for acceptable inclusion criteria. Methods were reviewed to ensure characteristics of studies fell within the parameters. Finally, 52 full text articles were read to draw a good representative sample. A sample of 12 individual studies and 8 systematic reviews that fit the scoping review criteria were ultimately chosen. Several studies were excluded due to author using the same study to write several papers, lack of reported evaluation tools, or, in the case of systematic reviews, use of the same individual studies [29] where multiple duplications in the review are used in the individual studies selected by the researchers and no new information was gained. Figure 1 displays the flow chart as to the database search and final article selection.

\section{Study characteristics Individual studies}

Twelve individual studies published between 2008 to 2017 were chosen, originating from: 3 Australia/Oceania, 3 Asia, 4 Europe, 1 North America and 1 South Africa. The workplace settings were: 4 healthcare, 1 education, 2 manufacturing, 2 governmental organizations, 2 retail, 1 airline and 2 studies did not report specific worksites but mentioned white-collar office employees as the target population. Interventions varied widely but all included increasing physical activity as a primary component. Physical activity (PA) modes were: 7 exercise programs, 1 weight-loss program, 1 wellness program, 1 PA counseling, 1 general health promotion program and 1 focused on reduction of sitting time.

The mean sample size of the 12 studies was 408 participants with ranges between 70 [30] to 1442 [31] participants. A sample size of $<200$ was observed in $33 \%$ ( $n$ $=4$ ) of the studies. Attrition was reported in all studies and ranged between $4.7-57 \%$ with an average of $30.8 \%$ over the entire length including follow-up periods which varied between 3 weeks to 12 months post intervention. 


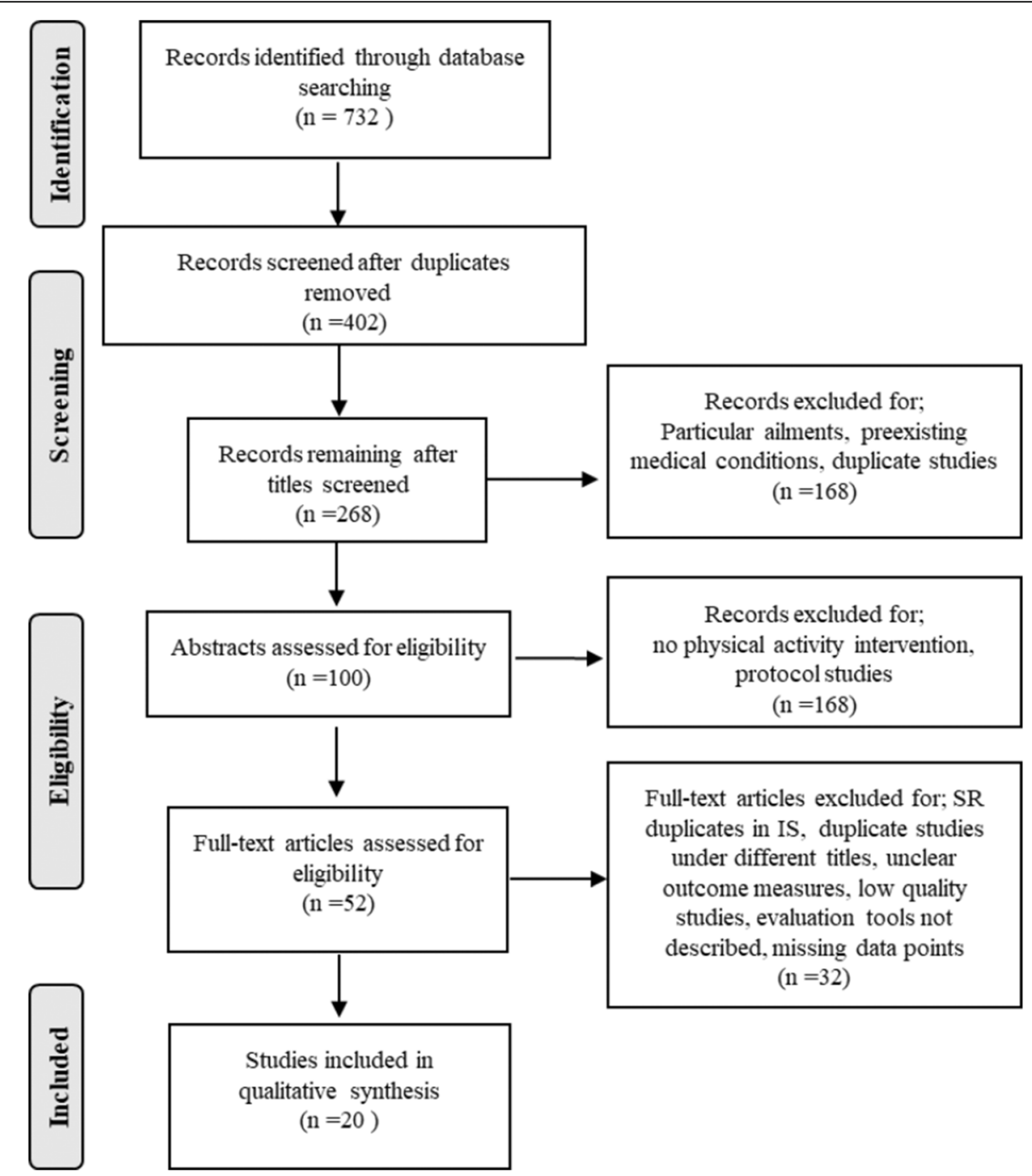

Fig. 1 Flow chart displaying study selection process

Study designs included: 5 RCT, 5 observational, 1 case-control and 1 quasi-experimental design (intervention group recruited separately from reference group). Quality grading was such: 5 received an 'A', 2 received a ' $\mathrm{B}$ ' and 5 received a ' $\mathrm{C}$ '. Table 1 displays study characteristics for individual studies.

\section{Systematic reviews}

Eight systematic reviews published between 2008 to 2017 were selected. Reviews originated from various countries; 2 studies did not disclose locations, 4 from Organization for Economic Co-operation and Development (OECD) developed countries, 1 included only European studies and 1 used studies from the USA/Australia/Europe. The worksite settings also varied from education, healthcare, commercial, governmental employees, blue collar settings to manufacturing. The physical activity modes included: increasing steps/walking promotions, active commuting (e.g. biking or walking to and from work), team sports, active workstations and various exercise classes with different intensity levels. The number of studies included in each review ranged from 15 to 138. Studies varied in population sizes with a mean of 5984 participants. The smallest reported study included in a systematic review had 10 participants [32] and the largest study had 79,070 participants [33]. Attrition data was reported in $25 \%(n=2)$ of the systematic reviews $[34,35]$ with an average of $23.5 \%$ loss to follow up. Three of the $8(37.5 \%)$ reviews reported study length ranging between 15 days to 12 years [33, 34, 36]. Systematic reviews included all study designs: 7 included RCTs, 5 included observational, 3 controlled before-after, 3 cross-sectional, 1 cohort trial, 1 quasi-experimental and 1 qualitative exploratory. For 
Table 1 Individual Study Characteristics

\begin{tabular}{|c|c|c|c|c|c|c|}
\hline Author & $\begin{array}{l}\text { Publication } \\
\text { Date }\end{array}$ & Country & Work Setting & $\begin{array}{l}\text { Sample } \\
\text { Size }\end{array}$ & auality & Intervention \\
\hline \multicolumn{7}{|l|}{ Individual Studies } \\
\hline Davey, J., et al. & 2009 & New Zealand & University Employees & 134 & C & Physical activity-steps \\
\hline Dishman, R., et al. & 2009 & $\begin{array}{l}\text { United States/ } \\
\text { Canada }\end{array}$ & Home Improvement Stores & 1442 & A & Physical activitysteps/**MVPA \\
\hline $\begin{array}{l}\text { Maruyama, C., et } \\
\text { al. }\end{array}$ & 2010 & Japan & $\begin{array}{l}\text { Health Insurance } \\
\text { Association }\end{array}$ & 101 & A & Nutrition/Physical Activitysteps \\
\hline $\begin{array}{l}\text { McEachan, R., et } \\
\text { al. }\end{array}$ & 2011 & UK & $\begin{array}{l}\text { Bus Company; Hospital; } \\
\text { Local Government; } \\
\text { National Government; } \\
\text { University }\end{array}$ & 1274 & $A$ & Physical activity-MVPA \\
\hline Morgan, PJ, et al. & 2012 & Australia & Tomago Aluminum & 110 & B & Weight lossnutrition/pedometer \\
\hline Edries, N., et al. & 2013 & South Africa & $\begin{array}{l}3 \text { Clothing Manufacturing } \\
\text { Companies }\end{array}$ & 90 & A & $\begin{array}{l}\text { Wellness program with }{ }^{* *} \mathrm{CBT} \text { and } \\
\text { exercise classes }\end{array}$ \\
\hline Chae, D., et al. & 2015 & South Korea & Airline Company & 70 & C & Physical activity-steps \\
\hline $\begin{array}{l}\text { Brakenridge, C.L., } \\
\text { et al. }\end{array}$ & 2016 & Australia & $\begin{array}{l}\text { Lendlease-International } \\
\text { Property and Infrastructure } \\
\text { Group }\end{array}$ & 153 & A & $\begin{array}{l}\text { Physical activity-reduced sitting } \\
\text { time }\end{array}$ \\
\hline $\begin{array}{l}\text { Hendricksen, l., } \\
\text { et al. }\end{array}$ & 2016 & Netherlands & Dutch Insurance Company & 433 & C & Lifestyle-MVPA/sedentary behavior \\
\hline Hori, H., et al. & 2016 & Japan & Not listed & 490 & C & Physical activity-steps \\
\hline Aittasalo, M., et al. & 2017 & Finland & $\begin{array}{l}12 \text { small-medium size } \\
\text { workplaces }\end{array}$ & 396 & C & $\begin{array}{l}\text { Physical Activity-reduce sitting } \\
\text { time }\end{array}$ \\
\hline Arrogi, A., et al. & 2017 & Belgium & Pharmaceutical Company & 300 & B & $\begin{array}{l}\text { Physical activity cousellingswim, } \\
\text { bike, run, walk }\end{array}$ \\
\hline
\end{tabular}

a Grading system is based on study design; A - RCT / B - Quazi-randomized trials / C - Observational Study / D - Other Evidence [28]

${ }^{*}$ MVPA - Moderate to vigorous physical activity

***CBT - Cognitive behavior therapy

consistency in this scoping review, grading scales were converted to the 'A-D' quality assessment based on the type of study designs reported in each systematic review, this was done in the same fashion as the individual studies. Table 2 displays study characteristics for systematic reviews.

\section{Outcomes}

\section{Measured outcomes}

A total of 9 'themed' outcome measures were found across the 20 studies. Physical Activity Level was the primary consideration therefore, this category included; step counts, decreased sedentary activity, increase of moderate to vigorous physical activity (MVPA), metabolic equivalents (METs), aerobic activity level, time spent playing sporting activities and active commuting. The other 8 'themes' included: Fitness, Motivation/Involvement/Self-efficacy, Nutrition, Management Promotion Support, Anthropometric Measurements, Bio-chemical Parameters, Work-related and Health-related Quality of Life (QoL)/ Well-being. Fitness was separated out from Physical Activity because it was only found in the systematic reviews and had specific biological tests performed for changes such as $\mathrm{VO}_{2}$ max, flexibility, endurance and strength tests such as 1-Repetition Max. As the main inclusion criterion was changes in physical activity level, this was used and measured in $100 \%$ of the studies $(n=20)$. Changes in anthropometric measurements such as BMI and body fat percentage were used in $65 \%(n=13)$ of the studies. Health Related QoL was measured in $60 \%$ of the studies $(n=12)$. Work related outcomes such as absenteeism and work stress were reported in $45 \%$ of the studies $(n=9)$. Management involvement was reported in only $20 \%(n=$ $4)$ and nutrition in $15 \%(n=3)$ of the studies. Changes in PA level was also associated as a causal factor for other outcome measures such as sleep quality $[22,37,38]$ or lower absenteeism rates [33, 38-42]. For example, an increase in daily steps leads to a decrease in reported employee sick days. All measured outcomes can be seen in Table 3. Measured Outcomes with a check next to the respective studies.

\section{Evaluation tools}

Three different categories of evaluation tools were found to measure the different outcomes: biologic, electronic and declarative. Electronic devices included anything that measured specific step counts or activity levels such as pedometers and accelerometers, biologic tools 
Table 2 Systematic Review Characteristics

\begin{tabular}{|c|c|c|c|c|c|c|c|}
\hline Author & $\begin{array}{l}\text { Publication } \\
\text { Date }\end{array}$ & Quality & Country & Work setting & \# of studies & Sample ranges & Intervention \\
\hline \multicolumn{8}{|l|}{ Systematic Reviews } \\
\hline Conn, V., et al. & 2009 & Not reported ${ }^{a}$ & Not reported & $\begin{array}{l}\text { Education/Health } \\
\text { Government } \\
\text { Manufacturing }\end{array}$ & 138 & $12-5038$ & $\begin{array}{l}\text { Physical Activity-Fitness } \\
\text { Motivation Education }\end{array}$ \\
\hline Vuillemin, A., et al. & 2011 & $\begin{array}{l}19=A \\
3=B \\
11=C\end{array}$ & Europe & Variety & 33 & $14-26,806$ & Physical Activity \\
\hline Schroer, S., et al. & 2013 & $\begin{array}{l}9=A \\
6=C\end{array}$ & $\begin{array}{l}\text { USA/Australia/ } \\
\text { Europe }\end{array}$ & Variety & 15 & $10-48,835$ & Physical Activity/Nutrition \\
\hline Amlani, N., et al. & 2014 & $\begin{array}{l}9=A \\
20=B \\
8=C\end{array}$ & $\begin{array}{l}\text { Developed } \\
\text { Countries }\end{array}$ & Variety & 37 & $43-79,070$ & Physical Activity \\
\hline Malik, S., et al. & 2014 & $\begin{array}{l}31=A \\
21=B \\
6=C\end{array}$ & Not reported & $\begin{array}{l}\text { Education/Health/ } \\
\text { Government/ } \\
\text { Commercial }\end{array}$ & 58 & $32-798$ & $\begin{array}{l}\text { Physical Activity/ Exercise/ } \\
\text { Counselling/Support Health } \\
\text { Promo Message }\end{array}$ \\
\hline Brinkley, A., et al. & 2016 & $\begin{array}{l}4=A \\
2=B \\
12=C\end{array}$ & $\begin{array}{l}\text { Developed } \\
\text { Countries }\end{array}$ & $\begin{array}{l}\text { Education/Health/ } \\
\text { Factory/Corporation }\end{array}$ & 18 & $30-2118$ & $\begin{array}{l}\text { Physical Activity-team } \\
\text { sports, group fitness, } \\
\text { team walking }\end{array}$ \\
\hline Shrestha, N., et al. & 2016 & $\begin{array}{l}14=A \\
2=B \\
4=C\end{array}$ & $\begin{array}{l}\text { High Income } \\
\text { Nations }\end{array}$ & Office workers & 20 & $25-443$ & $\begin{array}{l}\text { Physical Activity- workplace } \\
\text { changes policy/counselling/ } \\
\text { information/Multiple } \\
\text { interventions }\end{array}$ \\
\hline Reed, J.L., et al. & 2017 & $\begin{array}{l}17=A \\
4=B \\
3=C\end{array}$ & $\begin{array}{l}\text { High Income } \\
\text { OECD Nations }\end{array}$ & Variety & 24 & $26-650$ & Physical Activity-MVPA/METs \\
\hline
\end{tabular}

${ }^{a}$ Grading system is based on study design; A - RCT / B - Quazi-randomized trials, prospective case control, non-RCT/ C - Observational, controlled before-after, qualitative exploratory, cross-sectional, quasi-experimental / D - Other Evidence [28]

NR authors reported RCT, observational and controlled before-after designs but not specific numbers of each

MVPA Moderate to vigorous physical activity, METs metabolic equavalents

included any method that measured levels of bio-chemical or anthropometric factors such as blood-glucose or body fat percentage $(\mathrm{BF} \%)$ and declarative included all participant reports such as perceived exertion in METs or self-reported questionnaires such as the International Physical Activity Questionnaire (IPAQ) or diaries. They were subsequently categorized into either subjective or objective formats. Researchers discovered 92 unique evaluation tools, of these, 27 were objective and 65 were subjective tools. Table 4 displays the number of unique subjective and/or objective tools used for the respective outcomes.

All biologic and electronic tools were categorized into objective evaluation tools as were 3 of the work related tools; making up 29.3\% $(n=27)$. These included connected objects such as pedometers, accelerometers and activity trackers. Biologic testing was also categorized in objective tools which included biomedical measurements such as $\mathrm{BMI}, \mathrm{BF} \%, \mathrm{VO}_{2}$ max, cholesterol and blood glucose. Work related measures included in this category were based on human resource data and medical records. Subjective methods made up $71 \%$ of the evaluation tools $(n=65)$. Subjective surveys, diaries and questionnaires were the favored tool and used in 100\% of the studies $(n=20)$. Physical activity was the primary outcome measure; it was measured via 6 objective and 20 subjective tools. The variety of unique questionnaires, electronic and biologic tools can be seen in (Additional file 1). The specific physical activity outcome for individual studies can be seen in more detail (see Additional file 2) and the same for systematic reviews (see Additional file 3).

\section{Discussion}

Several systematic reviews exist on workplace physical activity interventions. This scoping review is the first of its kind to synthesize information from both systematic reviews and individual studies with the key goal in mind to identify what outcomes are considered as physical activity and how these outcomes are measured. Many previous reviews mention the heterogeneity of WHPs [17, 32, 34-36, 39]. The present review took a broad and inclusive approach and in doing so, several key gaps were identified: (1) difficulty in the comparability of studies, (2) high attrition rates and (3) lack of proven sustainability. Considering the increased interest in this subject for all stakeholders including public health professionals, researchers, corporations and employees, it is necessary to 
Table 3 Measured Outcomes

\begin{tabular}{|c|c|c|c|c|c|c|c|c|c|}
\hline Study & PA Level & $\begin{array}{l}\text { Mot/Involve } \\
\text { /Self-eff }\end{array}$ & Nutrition & Management & Anthropometric & Biochemical & Work Related & $\begin{array}{l}\text { Health Related } \\
\text { QoL/Well-Being }\end{array}$ & Fitness \\
\hline \multicolumn{10}{|l|}{ Individual Studies } \\
\hline Davey, et al & $\sqrt{ }$ & $\sqrt{ }$ & & & & & & $\sqrt{ }$ & \\
\hline Dishman, et al & $\sqrt{ }$ & $\sqrt{ }$ & & $\sqrt{ }$ & & & & & \\
\hline Maruyama, et al & $\sqrt{ }$ & & $\sqrt{ }$ & & $\sqrt{ }$ & $\sqrt{ }$ & & & \\
\hline McEachan, et al & $\sqrt{ }$ & & & & $\sqrt{ }$ & $\sqrt{ }$ & & $\sqrt{ }$ & \\
\hline Morgan, et al & $\sqrt{ }$ & & & & $\sqrt{ }$ & $\sqrt{ }$ & $\sqrt{ }$ & $\sqrt{ }$ & \\
\hline Edries, et al & $\sqrt{ }$ & & & & $\sqrt{ }$ & & $\sqrt{ }$ & $\sqrt{ }$ & \\
\hline Chae, et al & $\sqrt{ }$ & $\sqrt{ }$ & & & $\sqrt{ }$ & & & & \\
\hline Brakenridge, et al & $\sqrt{ }$ & & & & $\sqrt{ }$ & $\sqrt{ }$ & $\sqrt{ }$ & $\sqrt{ }$ & \\
\hline Hendricksen, et al & $\sqrt{ }$ & & $\sqrt{ }$ & $\sqrt{ }$ & $\sqrt{ }$ & $\sqrt{ }$ & $\sqrt{ }$ & $\sqrt{ }$ & \\
\hline Hori, et al & $\sqrt{ }$ & & & & & & & $\sqrt{ }$ & \\
\hline Aittasalo, et al & $\sqrt{ }$ & & & & & & $\sqrt{ }$ & $\sqrt{ }$ & \\
\hline Arrogi, et al & $\sqrt{ }$ & $\sqrt{ }$ & & $\sqrt{ }$ & $\sqrt{ }$ & $\sqrt{ }$ & & $\sqrt{ }$ & \\
\hline \multicolumn{10}{|l|}{ Reviews } \\
\hline Conn, et al & $\sqrt{ }$ & & & & $\sqrt{ }$ & $\sqrt{ }$ & $\sqrt{ }$ & $\sqrt{ }$ & $\sqrt{ }$ \\
\hline Vuillemin, et al & $\sqrt{ }$ & & & & $\sqrt{ }$ & & & & $\sqrt{ }$ \\
\hline Schroer, et al & $\sqrt{ }$ & & $\sqrt{ }$ & $\sqrt{ }$ & $\sqrt{ }$ & & & & \\
\hline Amlani, et al & $\sqrt{ }$ & & & & & & $\sqrt{ }$ & & \\
\hline Malik, et al & $\sqrt{ }$ & & & & & & & & \\
\hline Brinkley, et al & $\sqrt{ }$ & $\sqrt{ }$ & & & $\sqrt{ }$ & $\sqrt{ }$ & $\sqrt{ }$ & $\sqrt{ }$ & $\sqrt{ }$ \\
\hline Shrestha, et al & $\sqrt{ }$ & & & & & & $\sqrt{ }$ & $\sqrt{ }$ & \\
\hline Reed, et al & $\sqrt{ }$ & & & & $\sqrt{ }$ & $\sqrt{ }$ & & & \\
\hline
\end{tabular}

Mot/Involve/Self-eff Motivation/Involvement/Self-Efficacy, QoL Quality of Life

create focused, well-designed studies with adequate post-intervention assessment periods in order to confirm efficacy and sustainability of the increased physical activity results achieved by the interventions [32, 33, 35, 39].

\section{Study comparability}

\section{Measured outcomes/evaluation tools}

Accurate and reliable measurements of physical activity are important in evaluating programs. Currently, no consensus exists as to the proper way to measure desired outcomes nor which evaluation tools are best used during workplace physical activity promotions. In order to justify time and associated costs [39] for public policy, consistency, reliability and validity is necessary to draw conclusions about the efficacy of interventions. The current lack of homogeneity in both measurement tools as well as what constitutes increased physical activity (steps, MVPA, METs, weight lost, reported time spent

Table 4 Number of unique objective and subjective evaluation tools for each outcome

\begin{tabular}{lcc}
\hline Outcome & Objective Tools $(n=27)$ & Subjective Tools $(n=65)$ \\
\hline Physical Activity Level & $6 / 22 \%$ & $20 / 31 \%$ \\
Motivation/Involvement/Self-efficacy & $7 / 26 \%$ & $9 / 14 \%$ \\
Fitness & & $5 / 8 \%$ \\
Nutrition & & $2 / 3 \%$ \\
Management & $4 / 15 \%$ & $12 / 19 \%$ \\
Anthropometric & $7 / 26 \%$ & $17 / 26 \%$ \\
Bio-chemical Parameters & $3 / 11 \%$ & \\
Work-Related & & \\
Health Related QoL/Well-being & & \\
\hline
\end{tabular}


playing sports) makes comparisons and effects difficult to interpret which leads to an incomplete ability to measure program impacts [33, 35, 39]. Over the 20 selected studies, 9 themed outcomes were measured through 92 evaluation tools as can be viewed in Additional file 1. A prime example: 26 different evaluation tools were utilized to measure physical activity outcomes. Based on this research, due to cost effectiveness and ease of distribution, self-report tools were the preferred method for measurement of all outcomes, of these, 9 had unknown validation status and 6 were not validated measurement tools. These can be subject to recall bias and overestimations and therefore effects should be interpreted with caution [43, 44]. The IPAQ is validated and currently used in many studies ( $n=$ 6), but has shown biased estimates of energy expenditure. It was suggested that developing a correction factor when using the IPAQ-LF could alleviate this bias [45]. Because of the reputable nature, validation status and ease of use, the IPAQ could form the basis for studies using questionnaires. In addition, the ability to modify the questionnaire according to the promotion, country context, study design, workplace size and budget while maintaining validation would grant more standardization and allow the discovery of potential new information. This would increase consistency among subjective evaluations and the ability to compare promotions, workplaces and regions.

Objective tools were also found to be used in many programs. Of these, the most widely adopted and validated tool was a pedometer, 12 studies reported using these. They are simple, easy to report data and cost effective. As a starting point, it is suggested that pedometers be incorporated into WHPs in order to give an objective measurement tool easing the ability to compare programs. By focusing on incorporating the more widely used subjective and objective measurement tools, they could form the basis for future research that is more consistent and homogeneous.

As has been demonstrated, the sheer amount of subjective tools and outcome variables makes it nearly impossible to compare interventions. In addition to the multiple subjective tools used for evaluation purposes, concrete markers of physical activity (MVPA) and an objective biomarker (BMI) are strongly encouraged [17, 33-36, 39]. These types of objective measurements will assist in showing outcomes are consistent with increasing physical activity levels that coincide with current health organization recommendations.

\section{Study characteristics}

As similar systematic reviews found, various study designs were utilized. These often presented inadequate sample sizes, lack of proper control group and no blinding [33]; all play major roles in minimizing bias which are important considerations when designing studies for public policy research [32, 33, 35, 36, 39]. Smaller sample sizes can deliver less accurate results and increases the possibility that impacts will not be transferable to the population $[8,30]$. In this research, $1 / 3$ of the individual studies have less than 200 participants.

In determining effectiveness, the quality of a study should be considered due to risk of various forms of bias previously mentioned. While this research employed a simple grading system, some systematic reviews used more rigorous grading, such as the RE-AIM framework, $[17,33-35,42]$ and others did not report a specific grading system [32, 39]. Random controlled trials are seen as best evidence in judging observed effects of an intervention on the predetermined outcome [46].

One final note, the fact that many different promotions run simultaneously adds a layer of difficulty in drawing conclusions as to the effectiveness of one intervention on outcomes measured [17, 32, 33, 35, 47]. An analysis of the effects of counseling on physical activity levels was undertaken but, two other physical activity interventions were simultaneously employed; multiple component programs have been shown to increase success [32, 47]. Thus, drawing a conclusion on the single effect of counseling is biased due to concurrent interventions.

\section{Attrition}

Average attrition rates varied between 25 and $31 \%$ in the systematic reviews and individual studies, respectively. Investigating loss to follow-up is important as it can help determine the effectiveness and sustainability of a program as well as barriers to the uptake of interventions. Some of these studies noted reasons for dropouts $[23,48]$ while others gave no mention but recognized high attrition as a study design fault [8, 17, 30, 35]. In addition, dropout rates have been reported as typically higher among those that benefit the most from physical activity interventions. In general, dropouts are found to have a higher BMI and/or report poorer health at baseline including higher fat mass and lower reported PA [30, 38, 47, 49]. Workplace physical activity programs targeting this particular group of at risk employees should be at the forefront of a well-designed intervention for permanent behavior change.

\section{Sustainability}

Program sustainability is a primary aim in order to convert research into practice so policies can be justified. Often, interventions are put in place for a short period. Measurement practices and tools should be relevant to the working population giving researchers reliable data. Measurements are taken several times throughout the intervention (minimum at the beginning and end) and then, on occasion, several months 
post intervention. Adequate assessment periods with long-term follow-up of 12 months or more post intervention are strongly suggested. Only 3 of the individual studies and 4 of the systematic reviews reported a 12-month or longer follow-up. It appears that in the short-term, physical activity levels raise among those participating. Long-term adoption of the increased activity level should be the primary goal of all stakeholders. This sentiment was an expressed concern by many other reviews [17, 32, 35, 39, 42] but not a particular aim built into programs. There remains a lack of studies and promotions seeking to improve the sustainability of health behaviors. In order to make an impact on worker's health, policies prepared with the goal of permanent adoption of programs should be a priority.

\section{Strengths and limitations}

This is the first scoping review to specifically address outcomes that are measured in Workplace Physical Activity Promotions. Secondly, we assessed how outcomes were evaluated with the particular tools used in the studies making note of both subjective and objective forms. To our knowledge, this is the first time research such as this has been completed. A third strength lies in the fact that both individual studies as well as systematic reviews were considered in order to be more inclusive. Nevertheless, several limitations to this scoping review are noted. (1) Dates are limited to studies published after 2008. If the dates were broadened, more studies could have been included. This would have enabled changes and trends in these interventions to be seen. (2) Four main databases were searched for eligible individual studies and systematic reviews. Broadening the search to more databases could have yielded more studies to include in the scoping review. (3) There is a possibility of publication bias due to preference for positive results. Many publications prefer to publish studies with positive results rather than report on studies that lacked significant findings. (4) There is a lack of applicability with studies before 2008. Studies done before the Global Action Plan for Worker's Health could yield different outcomes and evaluation tools. (5) It is difficult to assess interventions in systematic reviews. Reviews report results based on their particular criteria making information extraction for this scoping review difficult. (6) The grading method may not be in depth enough to consider all types of quality in studies. Scoping reviews do not consider bias as do systematic reviews therefore, this was not taken into account during the quality assessment. A more in depth system using study design, population size, blinding and use of a matched control group could be constructed.

\section{Conclusion}

Current evidence remains mixed as to the effectiveness of workplace health promotions [17, 32-36, 39, 42]. The workplace appears to be a prime pathway to reach many sedentary adults but, lack of homogeneous, consistent, quality data exists to conclude if interventions are effective and sustainable. In this review, we analyzed studies conducted in the workplace that explicitly included a physical activity component. Of particular interest was identifying the outcomes measured as physical activity and how those outcomes were evaluated. Inconclusive evidence combined with multiple measured outcomes and the lack of standardized evaluation tools makes determining impacts difficult. Large heterogeneity exists in regard to data collection methods for the measured outcomes in most studies. Improvements to methodology can aid in the evaluation of WHPs thereby increasing the likelihood of employers finding such interventions effective for their staff. Consistent study designs with standard, validated evaluation tools will help to combat these issues. In this research, every study relied upon subjective questionnaires to gather information but, the heterogeneous nature led to unclear outcomes and comparison difficulties. The questionable nature of validity and reliability of the effects is noted. Standardizing questionnaires for particular outcomes could alleviate this concern as well as ensure studies and interventions have comparable data. The last several decades has seen an explosion of WHPs. As they gain momentum in the public health sector, development of a best practices guide is warranted in order to establish comparable, reliable and valid data collection across multiple workplace sizes, programs and geographical regions. Physical activity interventions based on research should ensure the involvement and ongoing support of all stakeholders. These improvements will ensure better tracking methods to justify programs allowing resources to be appropriately targeted leading to the best, most sustainable health outcomes.

\section{Additional files} Additional file 1: Electronic, Biologic, Self-report Evaluation tools and
Outcome Measure. (DOCX $22 \mathrm{~kb}$ )

Additional file 2: Individual study Physical Activity Outcomes. (DOCX 18 $\mathrm{kb})$

Additional file 3: Review Physical Activity Outcomes. (DOCX 19 kb)

\section{Abbreviations}

BF\%: Body fat percentage; BMI: Body mass index; CBT: Cognitive behavior therapy; CDC: Centers for Disease Control; IPAQ(-LF): International Physical Activity Questionnaire (-long form); METs: Metabolic equivalents; MVPA: Moderate to vigorous physical activity; NCDs: Non-communicable diseases; NIH: National Institute of Health; OECD: Organization for Economic Co-operation and Development; PA: Physical activity; QoL: Quality of life; $\mathrm{RCT}$ : Randomized control trial; $\mathrm{ROI}$ : Return on investment; $\mathrm{VO}_{2}$ max: Maximal 
oxygen consumption; WHO: World Health Organization; WHP: Worksite health promotions

\section{Acknowledgements}

The authors thank L'Institut National du Sport, de L'Expertise et de La Performance (INSEP), all team members at L'Institut de recherche biomédicale et d'épidémiologie du sport (IRMES) and Sorbonne Paris Cité (SPC) for their full support.

\section{Funding}

No outside funding was received for this review.

\section{Availability of data and materials}

Data sharing is not applicable to this article as no datasets were generated or analyzed during the current study.

\section{Authors' contributions}

SJ and JPR designed the research protocol, performed and analyzed the research. SJ and JU performed the search. Where questions arose, GB, JPR and JFT advised on article inclusion. SJ and JPR designed and tested the extraction forms. SJ and JPR designed the Tables. SJ wrote the manuscript. $J U, G B, A M, J F T$ and JPR read and revised the manuscript. All authors read and approved the final manuscript

\section{Ethics approval and consent to participate}

Not applicable

\section{Consent for publication}

Not applicable

\section{Competing interests}

The authors declare they have no competing interest

\section{Publisher's Note}

Springer Nature remains neutral with regard to jurisdictional claims in published maps and institutional affiliations.

\section{Author details}

${ }^{1}$ Institut de Recherche bio-Médicale et d'Épidémiologie du Sport (IRMES), Institut National du Sport de l'Expertise et de la Performance (INSEP), 11 avenue du Tremblay, 75012 Paris, France. ${ }^{2}$ Université Paris Descartes, EA 7329, Sorbonne Paris Cité, Paris, France. ${ }^{3}$ École des hautes études en santé publique (EHESP), Université Sorbonne Paris Cité, Rennes, France. ${ }^{4}$ Centre de Recherche Épidémiologie et Statistique Sorbonne Paris Cité (CRESS), METHODS Team, INSERM U1153, Université Sorbonne Paris Cité, Paris, France. ${ }^{5}$ Centre d'Investigations en Médecine du Sport (CIMS), Hôtel-Dieu, Assistance Publique - Hôpitaux de Paris, Paris, France. ${ }^{6}$ Research LAboratory for Interdisciplinary Studies (RELAIS), Paris, France.

\section{Received: 11 April 2018 Accepted: 20 August 2018}

Published online: 25 August 2018

\section{References}

1. Bhurosy T, Jeewon R. Overweight and obesity epidemic in developing countries: a problem with diet, physical activity, or socioeconomic status? Scientific World Journal. 2014;2014:964236.

2. WHO. Obesity and overweight. 2016.

3. Centers for Disease Control and Prevention. Adult Obesity Causes \& Consequences | Overweight \& Obesity | CDC. 2012. Available from: https:// www.cdc.gov/obesity/adult/causes.htm

4. WHO. Global Strategy on Diet, Physical Activity and Health: Physical Activity and Adults. 2017. Available from: http://www.who.int/dietphysicalactivity/ factsheet adults/en/

5. D.E. Bloom, Cafiero ET, Jané-Llopis E, Abrahams-Gessel S, Bloom LR, Fathima $S$, et al. The Global Economic Burden of Non-communicable Diseases (September 2011). 2011 [cited 2018 Mar 30]. Available from: http://apps. who.int/medicinedocs/en/d/Js18806en/

6. Lee I-M, Shiroma EJ, Lobelo F, Puska P, Blair SN, Katzmarzyk PT. Impact of physical inactivity on the World's major non-communicable diseases. Lancet. 2012;380:219-29.
7. WHO. Health-enhancing physical activity (HEPA) Policy Audit Tool (PAT) 2011

8. Davey J, Fitzpatrick M, Garland R, Kilgour M. Adult participation motives: empirical evidence from a workplace exercise Programme. Eur Sport Manag Q. 2009;9:141-62.

9. de Nazelle A, Nieuwenhuijsen MJ, Antó JM, Brauer M, Briggs D, BraunFahrlander $C$, et al. Improving health through policies that promote active travel: a review of evidence to support integrated health impact assessment. Environ Int. 2011;37:766-77.

10. Garber CE, Blissmer B, Deschenes MR, Franklin BA, Lamonte MJ, Lee I-M, et al. American College of Sports Medicine position stand. Quantity and quality of exercise for developing and maintaining cardiorespiratory, musculoskeletal, and neuromotor fitness in apparently healthy adults: guidance for prescribing exercise. Med Sci Sports Exerc. 2011;43:1334-59.

11. WHO. Country work. 2018 [cited 2018 Mar 30]. Available from: http://www euro.who.int/en/health-topics/disease-prevention/physical-activity/countrywork

12. ENWHP. Luxembourg Declaration on Workplace Health Promotion. 2007.

13. WHO E. Steps to health: a European framework to promote physical activity for health. 2007.

14. Goetzel RZ, Ozminkowski RJ. The health and cost benefits of work site health-promotion programs. Annu Rev Public Health. 2008;29:303-23.

15. Frantz JM, Ngambare R. Physical activity and health promotion strategies among physiotherapists in Rwanda. Afr Health Sci. 2013;13:17-23.

16. Maruyama C, Kimura M, Okumura H, Hayashi K, Arao T. Effect of a worksite-based intervention program on metabolic parameters in middle-aged male white-collar workers: a randomized controlled trial. Prev Med. 2010:51:11-7.

17. Vuillemin A, Rostami C, Maes L, Van Cauwenberghe E, Van Lenthe FJ, Brug J, et al. Worksite physical activity interventions and obesity: a review of European studies (the HOPE project). Obes Facts. 2011;4:479-88.

18. Centers for Disease Control and Prevention. Worksite Physical Activity Physical Activity | CDC. 2016. Available from: https://www.cdc.gov/ physicalactivity/worksite-pa/index.htm

19. Nassif H, Brosset N, Guillaume M, Delore-Milles E, Tafflet M, Buchholz F, et al. Evaluation of a randomized controlled trial in the management of chronic lower back pain in a French automotive industry: an observational study. Arch Phys Med Rehabil. 2011;92:1927-1936.e4.

20. Mazzola JJ, Moore JT, Alexander K. Is work keeping us from acting healthy? How workplace barriers and facilitators impact nutrition and exercise behaviors. Stress Health J Int Soc Investig Stress. 2017;33:479-89.

21. Toscos T, Consolvo S, McDonald DW. Barriers to physical activity: a study of self-revelation in an online community. J Med Syst. 2011;35:1225-42.

22. Aittasalo M, Livson M, Lusa S, Romo A, Vähä-Ypyä H, Tokola K, et al. Moving to business - changes in physical activity and sedentary behavior after multilevel intervention in small and medium-size workplaces. BMC Public Health. 2017:17:319.

23. McEachan RRC, Lawton RJ, Jackson C, Conner M, Meads DM, West RM. Testing a workplace physical activity intervention: a cluster randomized controlled trial. Int J Behav Nutr Phys Act. 2011;8:29.

24. Lichtman SW, Pisarska K, Berman ER, Pestone M, Dowling H, Offenbacher $\mathrm{E}_{\text {, }}$ et al. Discrepancy between self-reported and actual caloric intake and exercise in obese subjects. N Engl J Med. 1992:327:1893-8.

25. The Joanna Briggs Institute. Chapter 11: Scoping reviews - JBI Reviewer's Manual. 2015 [cited 2018 Mar 30]. Available from: https://reviewersmanual. joannabriggs.org/display/MANUAL/Chapter+11\%3A+Scoping+reviews

26. Liberati A, Altman DG, Tetzlaff J, Mulrow C, Gøtzsche PC, loannidis JPA, et al. The PRISMA statement for reporting systematic reviews and metaanalyses of studies that evaluate health care interventions: explanation and elaboration. PLoS Med. 2009:6:e1000100.

27. WHO. Global Plan of Action on Workers' Health (2008-2017): Baseline for Implementation 2013. Available from: http://www.who.int/occupational_ health/who_workers_health_web.pdf

28. Petrisor $B$, Bhandari $M$. The hierarchy of evidence: levels and grades of recommendation. Indian J Orthop. 2007;41:11-5

29. Freak-Poli RLA, Cumpston M, Peeters A, Clemes SA. Workplace pedometer interventions for increasing physical activity. Cochrane Database Syst Rev. 2013. Issue 4. Art. No:CD009209.

30. Chae D, Kim S, Park Y, Hwang Y. The effects of an academic--workplace partnership intervention to promote physical activity in sedentary office workers. Workplace Health Saf. 2015;63:259-66. 
31. Dishman RK, DeJoy DM, Wilson MG, Vandenberg RJ. Move to improve: a randomized workplace trial to increase physical activity. Am J Prev Med. 2009;36:133-41.

32. Schröer S, Haupt J, Pieper C. Evidence-based lifestyle interventions in the workplace--an overview. Occup Med Oxf Engl. 2014;64:8-12.

33. Amlani NM, Munir F. Does physical activity have an impact on sickness absence? A review. Sports Med Auckl NZ. 2014;44:887-907.

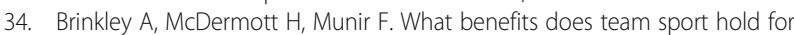
the workplace? A systematic review. J Sports Sci. 2017;35:136-48.

35. Malik SH, Blake H, Suggs LS. A systematic review of workplace health promotion interventions for increasing physical activity. $\mathrm{Br} J$ Health Psychol. 2014;19:149-80.

36. Reed JL, Prince SA, Elliott CG, Mullen K-A, Tulloch HE, Hiremath S, et al. Impact of workplace physical activity interventions on physical activity and Cardiometabolic health among working-age women: a systematic review and meta-analysis. Circ Cardiovasc Qual Outcomes. 2017;10

37. Hori H, Ikenouchi-Sugita A, Yoshimura R, Nakamura J. Does subjective sleep quality improve by a walking intervention? A real-world study in a Japanese workplace BMJ Open. 2016;6:e011055.

38. Morgan PJ, Collins CE, Plotnikoff RC, Cook AT, Berthon B, Mitchell S, et al. The impact of a workplace-based weight loss program on workrelated outcomes in overweight male shift workers. J Occup Environ Med. 2012;54:122-7.

39. Conn VS, Hafdahl AR, Cooper PS, Brown LM, Lusk SL. Meta-analysis of workplace physical activity interventions. Am J Prev Med. 2009;37:330-9.

40. Edries $\mathrm{N}$, Jelsma J, Maart $\mathrm{S}$. The impact of an employee wellness programme in clothing/textile manufacturing companies: a randomised controlled trial. BMC Public Health. 2013;13:25.

41. Hendriksen IJM, Snoijer M, de Kok BPH, van Vilsteren J, Hofstetter H. Effectiveness of a multilevel workplace health promotion program on vitality, health, and work-related outcomes. J Occup Environ Med. 2016; 58:575-83.

42. Shrestha N, Kukkonen-Harjula KT, Verbeek JH, ljaz S, Hermans V, Bhaumik S, Workplace interventions for reducing sitting at work. Cochrane Database Syst Rev. 2016:3:CD010912.

43. Taber DR, Stevens J, Murray DM, Elder JP, Webber LS, Jobe JB, et al. The effect of a physical activity intervention on bias in self-reported activity. Ann Epidemiol. 2009;19:316-22.

44. Sylvia LG, Bernstein EE, Hubbard JL, Keating L, Anderson EJ. Practical guide to measuring physical activity. J Acad Nutr Diet. 2014;114:199-208.

45. Maddison R, Ni Mhurchu C, Jiang Y, Vander Hoorn S, Rodgers A, Lawes CM, et al. International Physical Activity Questionnaire (IPAQ) and New Zealand Physical Activity Questionnaire (NZPAQ): a doubly labelled water validation. Int J Behav Nutr Phys Act. 2007;4:62

46. Sibbald B, Roland M. Understanding controlled trials: why are randomised controlled trials important? BMJ. 1998:316:201.

47. Arrogi A, Schotte A, Bogaerts A, Boen F, Seghers J. Short- and longterm effectiveness of a three-month individualized need-supportive physical activity counseling intervention at the workplace. BMC Public Health. 2017:17:52.

48. Brakenridge CL, Fjeldsoe BS, Young DC, Winkler EA, Dunstan DW, Straker LM, et al. Evaluating the effectiveness of organisational-level strategies with or without an activity tracker to reduce office workers' sitting time: a cluster-randomised trial. Int J Behav Nutr Phys Act. 2016;13:115.

49. Robroek SJW, Lindeboom DEM, Burdorf A. Initial and sustained participation in an internet-delivered long-term worksite health promotion program on physical activity and nutrition. J Med Internet Res. 2012;14:e43.

Ready to submit your research? Choose BMC and benefit from:

- fast, convenient online submission

- thorough peer review by experienced researchers in your field

- rapid publication on acceptance

- support for research data, including large and complex data types

- gold Open Access which fosters wider collaboration and increased citations

- maximum visibility for your research: over $100 \mathrm{M}$ website views per year

At $\mathrm{BMC}$, research is always in progress.

Learn more biomedcentral.com/submissions 